\title{
Water column transparency and the distribution of spectrally distinct forms of phycoerythrin- containing organisms
}

\author{
A. Michelle Wood ${ }^{1,2,3, *}$, David A. Phinney ${ }^{3}$, Charles S. Yentsch ${ }^{3}$ \\ ${ }^{1}$ Department of Biology, University of Oregon, Eugene, Oregon 97403 , USA \\ ${ }^{2}$ Naval Research Laboratory, Code 7330, Stennis Space Center, Mississippi 39529, USA \\ ${ }^{3}$ Bigelow Laboratory for Ocean Science, West Boothbay Harbor, Maine 04575, USA
}

\begin{abstract}
Predominance of Type I (phycourobilin-containing) and Type II (phycourobilin-lacking) phycoerythrins (PE) was examined using scanning fluorescence spectroscopy at 176 stations in the northwestern Atlantic off the northeast coast of the United States. Simultaneous optical measurements were made at 75 stations, permitting an analysis of the distribution of spectral types of PE-containing organisms based on geographic position of the stations and on the relative penetration of blue and green wavelengths of light. Stations dominated by Type I PE occurred almost exclusively in very transparent water with high transmissivity for blue light [downwelling attenuation coefficient; $K_{\mathrm{d}}(440)<$ 0.12 ] and relatively low attenuation of blue light relative to green light. This pattern was reversed for Type II PE, which dominated in less transparent waters with relatively high attenuation of blue light relative to green light. TYpe II PE tended to dominate on the continental shelf and slope, and Type I PE tended to dominate in the Sargasso Sea. Regardless of geographic location, there was a transition from dominance by Type I PE to Type II PE as the ratio $K_{d}(440) / K_{d}(550)$ exceeded 1.25 . Our data suggest that optical parameters are important niche dimensions for marine Synechococcus and that nearshore waters may be classified optically by phycoerythrin characterization.
\end{abstract}

KEY WORDS: Phycoerythrin $\cdot$ Synechococcus $\cdot$ Ocean color $\cdot$ Optics

\section{INTRODUCTION}

The need for enhanced absorption in the blue region of the spectrum has been invoked to explain the predominance of 'high phycourobilin' forms of Synechococcus in oceanic waters, and it is widely accepted that the predominant forms of marine Synechococcus in blue water contain a phycoerythrin (PE) with a high proportion of phycourobilin (PUB) to phycoerythrobilin (PEB) chromophores (Wood 1985, Campbell \& Iturriaga 1988, Olson et al. 1988, 1990, Wyman 1992). Intuitively, this seems adaptive since the downwelling attenuation coefficient $\left(K_{d}\right)$ in oceanic regions is much lower in the blue than in the green region of the spectrum and the absorption maximum of PUB is blue-

\footnotetext{
- Correspondence address: Department of Biology, University of Oregon, Eugene, Oregon 97403, USA

E-mail: miche@darkwing.uoregon.edu
}

shifted relative to that of PEB (compare $495-500 \mathrm{~nm}$ for $\lambda_{\text {AbsMax }}$ of PUB to $540-575 \mathrm{~nm}$ for $\lambda_{\text {AbsMax }}$ of PEB; cf. Glazer 1985, Sidler 1994). Blue water environments, where nearly all the absorbance of light is determined by the inherent optical properties of water, living phytoplankton, and recent derivatives of phytoplankton, have been classed as Case 1 waters by Morel \& Prieur (1977). Case 1 waters are generally inclusive of water types I, II, and III as described by Jerlov (1976).

Nearshore waters over continental shelves and in estuaries, however, often contain particulate or dissolved organic matter of terriginous or benthic origin that is not recently derived from phytoplankton. Most of this material absorbs light at shorter wavelengths and these 'yellow substance'-dominated waters are classified optically as Case 2 waters (Morel \& Prieur 1977, Gordon \& Morel 1983). In these environments where $K_{\mathrm{d}}$ at $440 \mathrm{~nm}$ can, in fact, be greater than $K_{\mathrm{d}}$ at $550 \mathrm{~nm}$ (Jerlov 1976, Kirk 1994), PE-containing organ- 
isms with PUB have no obvious chromatic advantage relative to organisms with a $\mathrm{PE}$ composed solely of $\mathrm{PEB}$ chromophores.

Olson et al. (1990) used dual beam flow cytometry to examine the relative proportion of high- and low-PUB forms of PE-containing Synechococcus in the North Atlantic and eastern Pacific. While populations at offshore stations were comprised almost entirely of cells with high PUB-forms of PE, the populations at shelf and slope stations were comprised of cells with a mixture of high and low-PUB PEs. Vernet et al. (1990) extracted $P E$ from the plankton at a single station off southern California and found the same low PUB-form of PE in samples from several depths. This Iow-PUB form of PE also dominated a sample collected at $20 \mathrm{~m}$ in the Celtic Sea (Wyman 1992). In the Black Sea, Shalapenok \& Shalapenok (1997) found that the proportion of cells with a PUB-lacking form of PE was inversely related to the Secchi depth, and it decreased from a high of $80 \%$ at a station with a Secchi depth of $1.6 \mathrm{~m}$ to a low of $0.0 \%$ at the most transparent station where the Secchi depth was $12.5 \mathrm{~m}$.

While these studies suggest that PE-containing cells in Case 2 waters will be characterized by low-PUB or PUB-lacking forms of $\mathrm{PE}$, there are no published data which permit an examination of the relationship between the forms of PE present in the water column and the in situ spectral distribution of available light. In this study we combine data from 15 cruises in the northeast Atlantic. PE types were characterized on the basis of the PE emission spectra, and the in situ light field was described on the basis of $K_{\mathrm{d}}(440)$ and $K_{\mathrm{d}}(550)$ measured at more than 70 stations. Overall, the data indicate that forms of PE that have either no PUB or very low amounts of PUB occur primarily in Case 2 waters, and that high-PUB forms are restricted to Case 1 waters.

\section{METHODS}

In their study of PE diversity in the Black Sea, Shalapenok \& Shalapenok (1997) relied on the fact that the emission maximum from PUB-lacking $P E$ is longer than the emission maximum from PUB-containing PE (Alberte et al. 1984, Wood et al. 1985). On fully corrected, quantum-counting spectrofluorometers, the difference is relatively small $(\sim 5 \mathrm{~nm})$, but on some optical systems the difference can be more than $10 \mathrm{~nm}$ (cf. Table 2 in Wood et al. 1985). In our work, this general approach was validated using cultures for which the PE has been purified and characterized: Synechococcus strain L1604 (=WH8018, CCMP838), which contains PE but lacks PUB, and Synechococcus strain DC2 (= WH7803, CCMP1334), which contains a PE that has both PUB and PEB chromophores (Alberte et al. 1984,
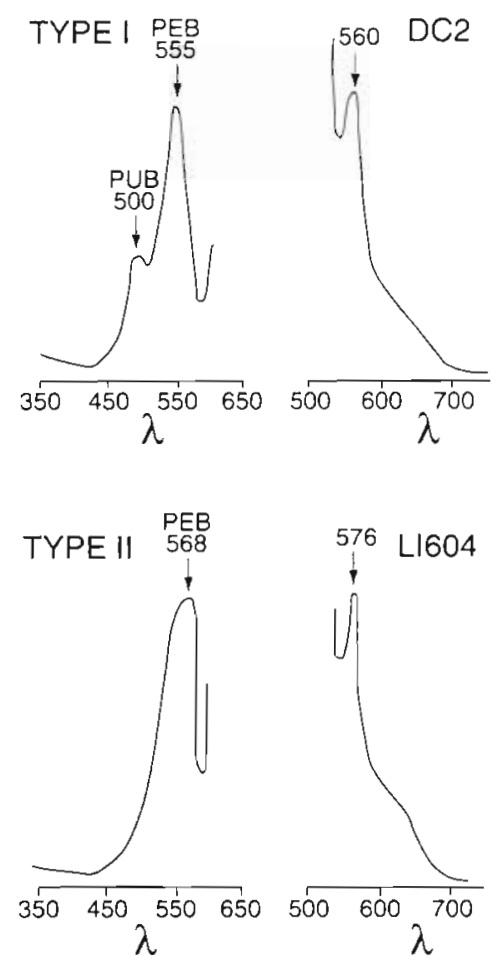

Fig. 1. Fluorescence excitation (left) and emission (right) spectra for cultures of cyanobacteria that synthesize the Type I (top) and Type II (bottom) phycoerythrin. As noted in the text, Type I spectral emission signatures are associated with strains which have PUB in at least one PE synthesized by the cells. The Type II spectral emission signatures are associated with strains that synthesize PEs comprised solely of PEB chromophores. The emission monochrometer was set at $630 \mathrm{~nm}$ for the excitation spectrum, which allowed resolution of the peak shape for excitation of PEB. The excitation monochrometer was set at $546 \mathrm{~nm}$ for emission spectra. Strain synonyms are given in the text

Wood et al. 1985, Ong \& Glazer 1991). Strains were grown under subsaturating light in $\mathrm{f} / 2$ medium (Guillard \& Ryther 1962) and filtered onto GF/F filters. Fluorescence excitation and emission spectra were obtained using a Baird Atomic spectrofluorometer as described elsewhere (Yentsch \& Yentsch 1979). The emission monochrometer was set at $620 \pm 10 \mathrm{~nm}$ to obtain the excitation spectrum for PE and the excitation monochrometer was set at $470 \pm 2 \mathrm{~nm}$ to obtain the emission spectrum for PE. As observed in previous spectra obtained from a number of strains with this instrument, the emission peak for the PUB-containing strain was more than $10 \mathrm{~nm}$ shorter than the emission peak for the PUB-lacking strains (Fig. 1; Wood et al. 1985).

Field samples were collected on 15 cruises in the Gulf of Maine and northeast Atlantic using Niskin bottles attached to the CTD rosette or hydrowire (Table 1). The number of depths sampled varied 
among cruises and also depended on the depth of the station, but samples were nearly always collected from the surface mixed layer and deep chlorophyll maximum (if present). For each sample, between 500 and $2000 \mathrm{ml}$ of water was filtered onto $\mathrm{GF} / \mathrm{F}$ filters and the emission spectrum for PE emission obtained as described above. Samples were classified as 'Type I' (presumably dominated by organisms with a PE composed of PUB and PEB) if the PE emission spectrum showed a single symmetrical peak between 555 and $565 \mathrm{~nm}$. Samples were classified as 'Type II' (presumably dominated by organisms with a PE composed of PEB chromophores only) if the fluorescence emission spectrum for samples excited at $546 \mathrm{~nm}$ showed a single symmetrical peak between 570 and $580 \mathrm{~nm}$. Samples classified as 'Type I' by these criteria include the full range of PUB-containing PEs, including those with relatively little PUB, like the dominant $\mathrm{PE}$ synthesized by our Type I reference strain (DC-2), and those with a large amount of PUB, like the PE made by strain WH8103 (cf. Ong \& Glazer 1991). PE excitation spectra were not run on all cruises, but when they were available, they were examined to confirm the classifications made using the emission spectra. Microscopic observation and additional fluorescence analysis were used to determine whether or not cryptomonads contributed to the PE fluorescence signature. Water column transparency at $440,520,550$, and $670 \mathrm{~nm}$ was measured at selected stations using a 4-channel submarine photometer as described in Phinney \& Yentsch (1991). Wavelength specificity for each channel was obtained using overlapping short- and long-pass interference filters to produce maximum transmission at the desired wavelength and a full bandwidth at half-maximum transmission of $20 \mathrm{~nm}$.

\section{RESULTS}

Spectra were obtained from more than 150 stations, including 75 stations where there was simultaneous measurement of the downwelling irradiance. In nearly all cases, the PE emission signature of the phytoplankton from any single station did not vary among samples collected at different depths; this allowed us to characterize each station as being dominated by either Type I or Type II PEs. Cryptomonads were not an important component of the PE-containing flora at any of the stations, and we believe that most of the PE signal measured in this study resulted from the presence of PE-containing marine Synechococcus.

The geographical distribution of stations with Type I and Type II PE emission signatures is plotted in Fig. 2. The majority of stations with a Type I PE emission signature occurred seaward of the continental slope, and the majority of stations with a Type II PE emission signature occurred on the continental shelf or slope. However, there were rare instances where Type I PE dominated the fluorescence signature at stations located well onto the continental shelf, and even more frequent instances where Type II PE dominated the water column on the slope and/or over the continental rise. At least 16 of our stations occurred in the Sargasso Sea, and these stations all showed the Type I PE emission signature.

Attenuation of downwelling irradiance was measured at $440,520,550$, and $670 \mathrm{~nm}$. Of particular interest is $K_{\mathrm{d}}(440)$, the attenuation of blue light, which is always very low in Case 1 waters and which increases as there is an increase in absorption by chlorophyll, humic substances, and particulate detritus ('givlin' sensu Kirk 1994). Also of interest is the attenuation of

Table 1. Cruise dates and sampling intensity on each cruise

\begin{tabular}{|c|c|c|c|c|}
\hline \multirow[t]{2}{*}{ Ship } & \multirow{2}{*}{ Cruise } & \multirow[t]{2}{*}{ Dates } & \multicolumn{2}{|c|}{ Samples collected (n) } \\
\hline & & & Fluorescence & Optics $\left(K_{d}\right)$ \\
\hline RV 'Oceanus' & OC68 & Aug $17-30,1979$ & 22 & 0 \\
\hline RV 'Eastward' & EA $07-80$ & Jul 21 -Aug 8,1980 & 21 & 0 \\
\hline RV 'Albatross IV' & AL81-04 & May 5-16, 1981 & 17 & 13 \\
\hline RV 'Atlantis II' & AII-110 & Sep 17 -Oct 7,1981 & 8 & 8 \\
\hline RV 'Knorr' & KN93 & Apr 19-May 6, 1982 & 9 & 8 \\
\hline RV 'Knorr' & KN95 & Jun $12-29,1982$ & 19 & 6 \\
\hline RV 'Knorr' & KN97 & Aug $7-24,1982$ & 11 & 5 \\
\hline RV 'Cape Hatteras' & $\mathrm{CH} 23-82$ & Aug $7-15,1982$ & 11 & 0 \\
\hline RV 'Endeavor' & EN90 & Sep $22-$ Oct 14,1982 & 5 & 1 \\
\hline RV 'Cape Hatteras' & $\mathrm{CH} 19-83$ & Jul $11-22,1983$ & 8 & 8 \\
\hline RV 'Gyre' & $84-G-7$ & May 25-31, 1984 & 8 & 7 \\
\hline RV 'Cape Hatteras' & $\mathrm{CH} 12-84$ & Jun $20-J u l 2,1984$ & 17 & 6 \\
\hline RV 'Cape Hatteras' & $\mathrm{CH} 15-85$ & Jun 23-Jul 3, 1985 & 7 & 7 \\
\hline RV 'Cape Hatteras' & $86-G-82$ & Jul 7-21, 1985 & 11 & 4 \\
\hline RV 'Gyre' & $86-G-82$ & Jul 1-8, 1986 & 2 & 2 \\
\hline
\end{tabular}




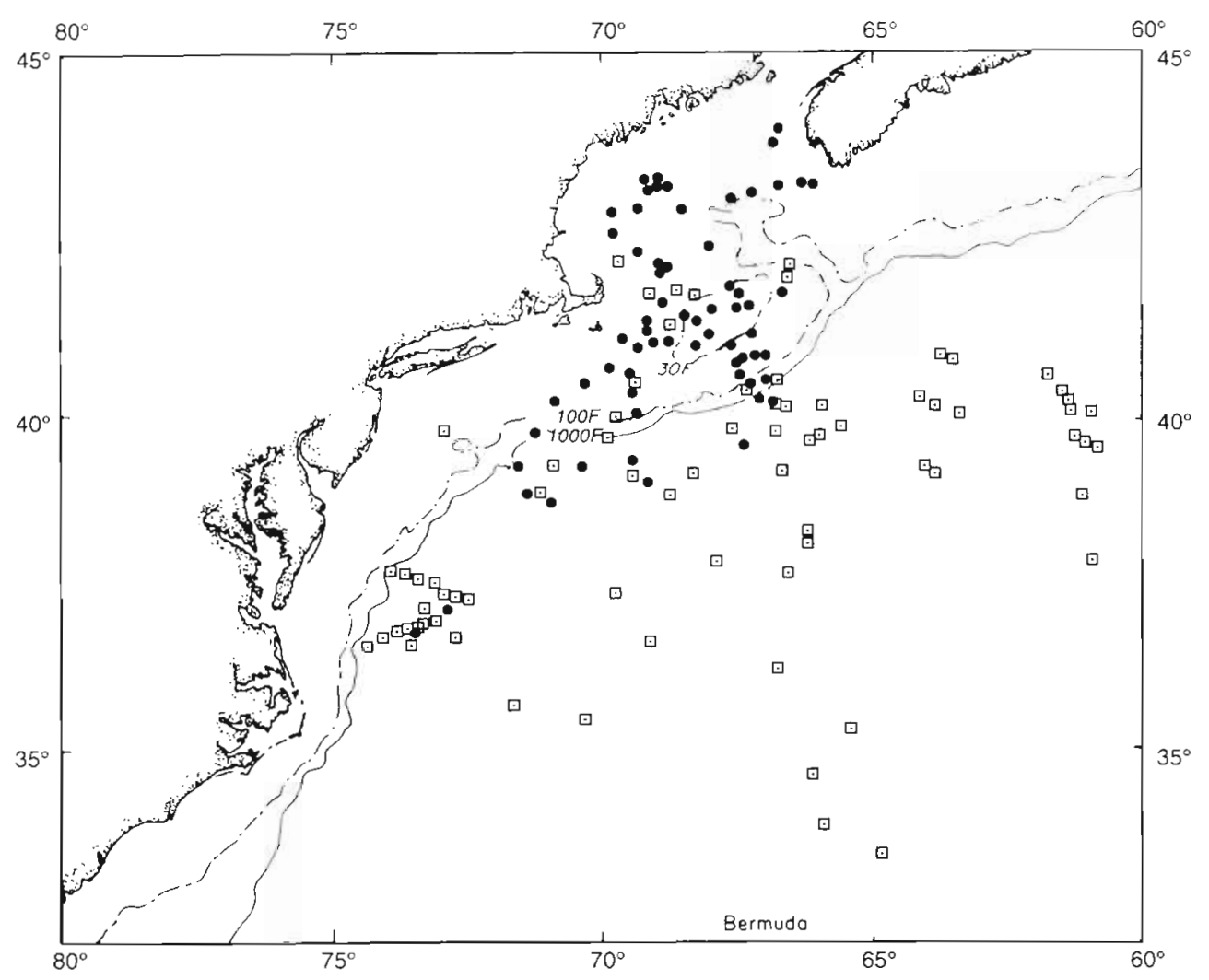

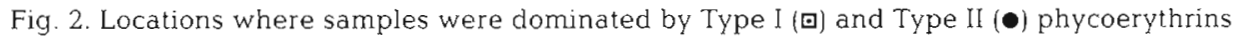

green light, which is absorbed by the phycobiliproteins. In this study $K_{\mathrm{d}}(520)$ was nearly identical to $K_{\mathrm{d}}(550)$ so we concentrate on $K_{\mathrm{d}}(550)$ because it corresponds directly to the transparency of the water at wavelengths absorbed maximally by PEB. PEB is found in all PEs, and accounts for all of the light $a b-$ sorption by PEs which lack PUB.

Over the range of environments we studied, $K_{\mathrm{d}}(440)$ ranged from 0.03 to 0.34 and $K_{\mathrm{d}}(550)$ ranged from 0.05 to 0.21 . The most extreme instance of low penetration of blue relative to green light was observed in 1984 at a station located over George's Bank $\left(41^{\circ} 38.5^{\prime} \mathrm{N}\right.$, $\left.69^{\circ} 26^{\prime} W\right)$ where the $K_{d}(440)$ was 0.29 and the $K_{d}(550)$ was 0.13 .

The association of Type I PE with 'blue water' is apparent in Fig. 3 which shows the frequency distribution of stations with Type I and Type II PE as a function of the attenuation of downwelling blue light. The majority of stations from which both optical and pigment data were collected were characterized as having Type I PE (45 out of 75 stations). Type I PE dominated the fluorescence emission signal in water where the $K_{\mathrm{d}}(440)$ ranged from 0.03 to 0.22 . This occurred most frequently in water where the $K_{\mathrm{c}}(440)$ was less than 0.15. Type II PE characterized 30 of the 75 stations where optical data were collected. Type II PE dominated the PE fluorescence emission signal in water where the $K_{d}(440)$ ranged from 0.05 to 0.33 , but was most common at stations where the $K_{d}(440)$ was greater than 0.15 .

Stations characterized by Type II PE rarely occurred in water with high overall penetration of blue light, nor did they occur when blue light was moderately attenuated as long as blue light penetrated the water column more efficiently than green light. In nearly all cases, green light penetrated the water column more efficiently than blue light at stations characterized by Type II PE. The frequency distribution of stations dominated by Type I and Type II PE emission signatures are plotted with respect to the ratio $K_{d}(440) / K_{d}(550)$ in Fig. 4. With only 2 exceptions, all 30 stations characterized by a Type II PE emission signature occurred where water column transparency was greater for green light than for blue light. The 2 stations where a Type II PE predominated in a water column where $K_{\mathrm{d}}(440) / K_{\mathrm{d}}(550)<1.0$ occurred just seaward of the shelf break in the mid-Atlantic Bight. These are the same 2 stations that appear as 'outliers' in the frequency distribution of stations dominated by Type II PEs in Fig. 3. In contrast, stations characterized by Type I PEs occur 

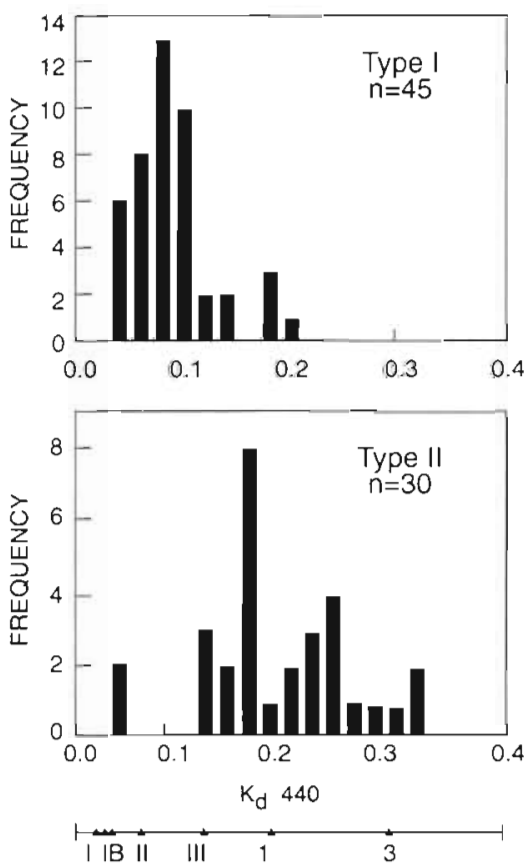

Fig. 3. Frequency distribution of samples dominated by Type 1 PE (top) and Type II PE (bottom) as a function of the attenuation of blue light. The bar along the bottom shows the $K_{\mathrm{d}}(440)$ for water masses of differing optical type, according to the classification scheme of Jerlov where types I-Ill are oceanic water masses, and 1-9 are coastal water masses

across a fairly wide range of $K_{d}(440) / K_{d}(550)$, although they are rare when $K_{\mathrm{d}}(440) / K_{\mathrm{d}}(550)$ exceeds 1.25 . Most stations where $K_{\mathrm{d}}(440) / K_{\mathrm{d}}(550)$ exceeded 1.25 were dominated by $\mathrm{PE}$ with a Type II fluorescence signature (Fig. 4)

\section{DISCUSSION}

The distribution of stations characterized by Type I and Type II PEs shown in Fig. 1 suggests a strongly delimited geographic niche for each type. Specifically, dominance by Type I forms appears to be restricted to oceanic regions with high transmittance of blue light and dominance by Type II forms appears to be restricted to continental shelf and continental slope ecosystems where the transmittance of green light exceeds that of blue light. A value of 1.25 for $K_{\mathrm{d}}(440) /$ $K_{\mathrm{d}}(550)$ generally coincides with the transition from dominance by Type I PEs to dominance by Type II PEs in the environments we studied. Additionally, the seaward boundary for the distribution of water masses dominated by Type II organisms roughly coincides with the hydrological boundary created by the Gulf Stream. Type I organisms clearly occur in a variety of hydrographic settings, including the Gulf Stream, the
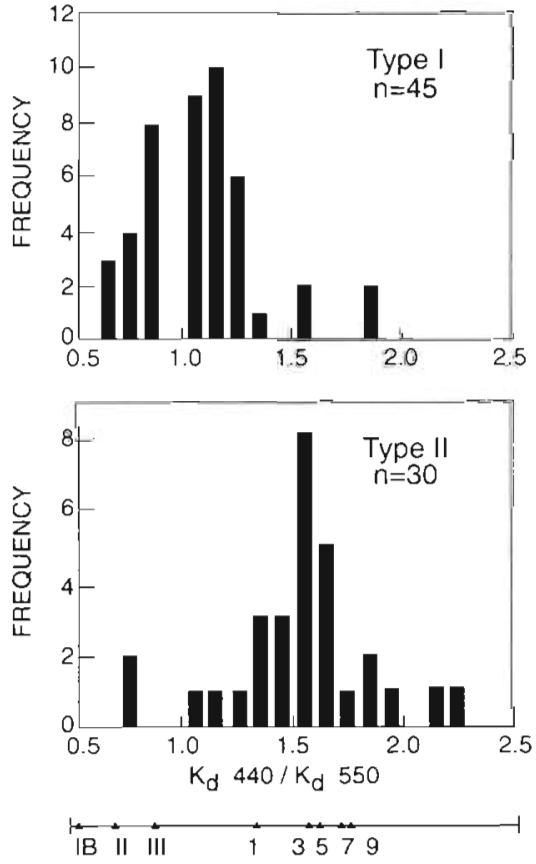

Fig. 4. Frequency distribution of samples dominated by Type I PE (top) and Type II PE (bottom) as a function of the relative attenuation of blue and green light. The bar along the bottom is as in Fig. 2, except the values shown are for $K_{\mathrm{d}}(440) / K_{\mathrm{d}}(550)$ in Jerlov's classification

Sargasso Sea, and some water masses that occur on the continental shelf and slope. While a Synechococcus strain containing Type II PE has been isolated from water collected in the Sargasso Sea (Strain WH7805, cf. Table 2 in Alberte et al. 1984), it appears that these organisms rarely, if ever, dominate the community of $\mathrm{PE}$-containing organisms in this environment.

\section{Optical biogeography}

We believe that the oceanographic color regimes are analogous to biogeographic provinces - that there are optical 'fences in the sea'. Do these fences really exist? How are they manifested and can they be observed? In this case, we hypothesize that the differences in the distribution of spectrally distinct forms of PE-containing organisms are due to the effects these different pigments have on the efficiency of photosynthesis in the natural light field. The patterns of distribution are believed to be due to differences in light absorption in the blue-green and green regions of the spectrum which depend on the type of PE synthesized. Since the types of PE synthesized by marine Synechococcus seem to be genetically programmed and invariant within genotypes (Wood et al. 1985, Ong \& Glazer 
1991, but see 'Discussion' in Olson et al. 1990), we suggest that natural selection maintains the dominance of pigment types in these different regions. Considering the differences in light absorption associated with the water masses where different PE forms dominate, it is natural to identify the local optical properties as the principal selective agent. The teleological argument is that organisms with Type I PE have a greater advantage to capture blue light photons that are abundant in clear open ocean waters. In coastal waters, where blue light is readily absorbed and the clarity of the water is less, PE-containing organisms have either lost, or never evolved, the capability to absorb blue light.

But this explanation poses a puzzle. Why do Type I organisms not occur as dominant organisms more frequently in Case 2 waters, particularly at the surface where blue and green photons are plentiful? Also, why do Type II organisms not occur in the surface layers of Case 1 waters where green light is still present? It is possible that cells with Type I PEs dominate blue water environments because they have much greater fitness in a time-averaged sense than cells with Type II PEs. If this were to explain the exclusion of organisms with Type II PEs from oceanic regions, then it implies that periods when the cells might be entrained into a shallow surface layer are counterbalanced by longer periods when deep mixing of cells results in an average light field dominated by blue wavelengths. Assuming both types of cells grow equally well when entrained to the surface layer, selection for the Type I forms during periods of deep mixing would ultimately lead to an extreme rarity of Type II cells in the water column. Future research in this direction should address differences in the spectral distribution of light, average mixed layer depth, and the residence time in that layer as well as tradeoffs associated with synthesizing different types of PEs in different environments

An alternate explanation for the distribution of Type I and Type II PEs observed in Fig. 1 is that the distribution of the 2 types is determined by circulation patterns in the North Atlantic. The delineation between the 2 types fits the North Atlantic salinity regimes as described by Worthington (1976). Type I cells are associated with higher salinity ocean surface water typical of the Sargasso Sea and Gulf Stream; Type II cells are associated with shelf waters of complex origin. The hydrographic hypothesis might also explain the sharpness of our biogeographic pigment boundary since the boundary between the western limit of Type I PEs and eastern limit of Type II PEs closely coincides with the cold wall of the Gulf Stream. As major features of interchange between slope waters and the Sargasso Sea, warm core rings would carry Type I organisms with them. The cluster of Type I stations near the continental margin at about $36^{\circ} \mathrm{N}$
(Fig. 2) was embedded in a warm core eddy (82-B cf. Roman et al. 1986), and this is probably an example of such transport. The major problem with the transport hypothesis is that the non-random association of different PE types with different water masses still implies that some form of natural selection is maintaining the dominance of one form over another in the different regions. Overall, the optical properties of waters in this region are regulated by the baroclinic effects of the density field due to general circulation (Yentsch 1989). Thus, optical patterns and hydrography cannot be separated in a straightforward manner and it is difficult to be certain which is the causative parameter. However, the close association of Type I and Type II PEs with water masses of different optical properties clearly identifies the spectral composition of the available light as an important niche parameter for PE-containing organisms.

A slightly more complex explanation of the pattern we observed is that there are coastal and oceanic species or genotypes of marine Synechococcus which differ in a wide range of physiological traits, including PE type. This explanation suggests that the type of PE produced by the dominant organisms is an indicator of the presence of rells with a wide range of additional adaptations to either oceanic or coastal conditions. It implies that the combined effects of natural selection by optical properties and other co-varying environmental parameters explains the association of Type I PEs with environments where $K_{\mathrm{d}}(440) / K_{\mathrm{d}}(550)$ is low and Type II PEs with environments where $K_{\mathrm{d}}(440) / K_{\mathrm{d}}(550)$ is high. This theory, which we propose as one which integrates the evolutionary history and contemporary ecology of the cells, would also explain the exclusion of Type I cells from the coastal environment where pigment type alone does not seem to provide any relative disadvantage. Further, this hypothesis predicts that Type II PEs might only dominate when a high value for the ratio $K_{d}(440) / K_{d}(550)$ occurs in waters of coastal origin (i.e. Case 2 waters) and not when $K_{\mathrm{d}}(440) / K_{\mathrm{d}}(550)$ is elevated by high concentrations of phytoplankton in Case 1 waters.

\section{Remote sensing}

The early pioneers in ocean optics produced classifications of water mass optics which explained changes in ocean color (e.g. Forel, as discussed in Sverdrup et al. 1942). Jerlov (1976) provided rather elaborate classifications which proposed optical distinctions between inshore, nearshore, and open ocean conditions. Recently those concerned with remote sensing of ocean color have reduced the classifications to fit into 2 categories (Case 1 and Case 2), largely to emphasize 
the relative importance of the absorption of light by the photosynthetic pigments of phytoplankton as opposed to contributions to water color by other biogenic and nonbiogenic substances. The remote sensing community recognized that in Case 1 waters changes in water color are largely due to changes in the abundance of phytoplankton. In Case 2 waters, color change is also influenced by the presence of dissolved and particulate colored substances. Most investigators are comfortable with the Case 1 and Case 2 classification when considering ocean extremes: coastal waters versus the open ocean. There is less of a consensus on the interpretation of gradients between the extremes, particularly when dealing with more highly colored waters near continental margins where the relative importance of phytoplankton and other absorbers is difficult to determine. Our results suggest that the PE fluorescence signature may provide a reliable method for distinguishing between Case 1 and Case 2 waters in these more complex situations.

Acknowledgements. This work was supported by ONR Grant 96PR00110-00 (to A.M.W.), by NASA Grant NAGW410 (to C.S.Y.), and by the Naval Research Laboratory through the 6.1 ARI 'Forced Upper Ocean Dynamics' under ONR Program element $61153 \mathrm{~N}$ and the NRL/ASEE summer faculty fellowship program. We thank Jean Garside and Jim Rollins for assistance with graphics and data analysis, and R. Arnone, A. Gldzer, R. Stdvn, and A. Weideman for comments on the manuscript. This is Bigelow Laboratory contribution 98001

\section{LITERATURE CITED}

Alberte RS, Wood AM, Kursar TA, Guillard RRL (1984) Novel phycoerythrins in marine Synechococcus spp. Characterization and evolutionary and ecological implications. Plant Physiol 75:732-739

Campbell L. Iturriaga R (1988) Identification of Synechococcus spp. in the Sargasso Sea by immunofluorescence and fluorescence excitation spectroscopy performed on individual cells. Limnol Oceanogr 33:1196-1201

Glazer AN (1985) Light harvesting by phycobilisomes. Annu Rev Biophys Biophys Chem 14:47-77

Gordon HR, Morel A (1983) Remote assessment of ocean color for interpretation of satellite visible imagery, a review. Lecture notes in coastal and estuarine studies, Vol 4. Springer-Verlag, New York

Guillard RRL, Ryther JH (1962) Studies on manne planktonic diatoms. I. Cyclotella nana Hustedt and Detonula confervacea (Cleve) Gran. Can J Microbiol 8:229-231

Jerlov NG (1976) Marine optics. Elsevier Amsterdam.

Editorial responsibility: Otto Kinne (Editor).

Oldendorf/Luhe, Germany
Kirk JTO (1994) Light and photosynthesis in aquatic ecosystems. Cambridge Univ Press, New York

Morel A, Prieur L (1977) Analysis of variations in ocean color. Limnol Oceanogr 22:709-722

Olson RJ, Chisholm SW, Zettler ER, Armbrust EV (1988) Analysis of Synechococcus pigment types in the sea using single and dual beam flow cytometry. Deep Sea Res 35: $425-440$

Olson RJ, Chisholm SW, Zettler ER, Armbrust EV (1990) Pigments, size, and distribution of Synechococcus in the North Atlantic and Pacific Oceans. Limnol Oceanogr 35 $45-58$

Ong LI, Glazer AN (1991) Phycoerythrins of marine unicellular cyanobacteria. I. Bilin types and location of energy transfer pathways in Synechococcus spp. phycoerythrins. J Biol Chem 266 9515-9527

Phinney DA, Yentsch CS (1991) On the contribution of particles to blue light attenuation in the sea. J Plankton Res 13: $143-152$

Roman MR, Yentsch CS, Gauzens AL, Phinney DA (1986) Grazer control of the fine-scale distribution of phytoplankton in warm-core Gulf Stream rings. J Mar Res 44:795-813

Shalapenok LS, Shalapenok AA (1997) Heterogenous pigment composition of phycoerythrin-containing picocyanobacteria Synechococcus in the Black Sea. Microbiology 66:80-84

Sidler WA (1994) Phycobilisome and phycobiliprotein structures. In: Bryant DA (ed) The molecular biology of cyanobacteria. Kluwer, Amsterdam, p 139-216

Sverdrup HU, Johnson MJ, Flemming RH (1942) The oceans. Prentice-Hall, Englewood Cliffs, NJ, p 88-89

Vernet M, Mitchell BG, Holm-Hansen O (1990) Adaptation of Synechococcus in situ determined by variability in intracellular phycoerythrin-543 at a coastal station off the southern California coast, USA. Mar Ecol Prog Ser 63: $9-16$

Wood AM (1985) Adaptation of the photosynthetic apparatus of marine ultraphytoplankton adapted to natural light fields. Nature 316:25-55

Wood AM, Horan PK, Muirhead K, Phinney DA, Yentsch CM, Waterbury JB (1985) Discrimination between types of pigments in marine Synechococcus by scanning spectroscopy, epifluorescence microscopy, and flow cytometry. Limnol Oceanogr 30:1303-1315

Worthington LV (1976) On the North Atlantic circulation. Johns Hopkins Oceanographic Studies, No. 6. Johns Hopkins Univ Press, Baltimore

Wyman M (1992) An in vivo method for the estimation of phycoerythrin concentrations in marine cyanobacteria (Synechococcus spp.). Limnol Oceanogr 37:1300-1306

Yentsch CS (1989) Estimation of 'new production' in the midNorth Atlantic. J Plankton Res 12:717-734

Yentsch CS, Yentsch CM (1979) Fluorescence spectral signatures: the characterization of phytoplankton populations by the use of excitation and emission spectra. J Mar Res $37: 471-483$

Submitted: August 27, 1997; Accepted: November 28, 1997 Proofs received from author(s): February 3, 1998 